\title{
Analysis of survival in patients with brain metastases treated surgically: Impact of age, gender, oncologic status, chemotherapy, radiotherapy, number and localization of lesions, and primary cancer site
}

José Marcus Rotta ${ }^{1}$

Daniella Brito Rodrigues ${ }^{1}$

Juliete Melo Diniz'

Bianca Medeiros de Abreu ${ }^{1}$

Fernanda Kamimura ${ }^{1}$

Ulysses Oliveira Sousa ${ }^{1}$

Ricardo Vieira Botelho'

Matheus Fernandes de Oliveira ${ }^{1}$

1. Neurosurgery Service of the Public Servant's Hospital of the State of São Paulo (HSPE-SP), São Paulo/SP, Brasil

\section{SUMMARY}

OBJECTIVE: To evaluate the survival of patients with brain metastases treated surgically according to the potentially involved factors. METHODS: 71 patients treated surgically were analyzed with the diagnosis of brain metastases during the period from January 2011 to November 2014, totaling 47 months of follow-up. The Kaplan-Meier curve method was used for survival analysis. Results: We evaluated 71 patients with brain metastases treated surgically, 44 female and 27 male, mean age of 60.1 years. According to the Karnofsky scale, 44 patients were classified with Karnofsky greater than or equal to 70 and 27 patients with Karnofsky inferior to 70 . Lung was the primary site most commonly found. Death occurred in twenty patients (28\%), and lung tumors were responsible for the most deaths. Twelve patients had supra and infratentorial metastases, fifty-nine only had supratentorial lesions, and lesions were multiple in twenty-eight patients and single in forty-three. Thirty patients were also treated with chemotherapy, eighteen with chemotherapy and radiation therapy, while only three received just radiotherapy. Survival analysis by Kaplan-Meier curve showed no statistical significance regarding age, histological type, location, Karnofsky, chemotherapy, and radiotherapy. There was statistical significance regarding gender.

CONCLUSION: The factors analyzed did not change survival rates, except for gender. This fact may probably be explained due to the systemic and diffuse behavior of cancer.

KEYWORDS: Neoplasm metastasis. Survival analysis. Neoplasms. Prognosis.

\section{INTRODUCTION}

Brain metastases are the most common type of intracranial tumors in adults, accounting for more than half of all cases. Typically, they are related to cancer stage but can also be the first manifestation of an undiagnosed malignancy. Brain metastases occur in 10 to
$30 \%$ of adults with disseminated tumors ${ }^{1-15}$. The presence of brain metastases implies an adverse shift in the course of the primary systemic disease due to its impact on survival and quality of life and to the development of potentially disabling symptoms ${ }^{1-10}$. 
Surgical resection of brain metastases is often indicated for the local control of cancer and may have impacts on the symptoms and course of the disease $^{10-15}$. Considering the importance of brain metastases and their impact on morbidity and mortality in patients with cancer, this study was designed to evaluate the survival of patients with brain metastases treated surgically and elucidate potential factors involved in progression.

\section{METHODS}

The study sample consisted of patients with cerebral metastasis consecutively admitted to Public Servant's Hospital of the State of São Paulo (HSPE) from January 2011 to November 2014. Patients enrolled in the study were then followed during treatment.

The study was observational and retrospective; all patients who received surgical treatment for a diagnosis of brain metastases during the period of interest were analyzed.

\section{Inclusion criteria}

Patients undergoing surgery as the first treatment strategy for brain metastases from systemic tumors were eligible for inclusion.

\section{Criteria for surgery}

Criteria used to indicate surgery for brain metastases were: in patients with single lesions, the presence of symptoms or lesion size $>2 \mathrm{~cm}$; in patients with multiple lesions, the presence of symptoms and larger lesions. Patients in palliative care and/or with very low functional status (Karnofsky score <40) were not considered candidates for surgery.

\section{Survival analysis}

Survival time was extracted from the HSPE registry of patient data. In questionable cases or when information was not available in the registry, direct telephone contact with family members was established.

\section{Analyzed factors}

The factors considered potentially related to survival were age, gender, histology, Karnofsky score, preoperative location (supratentorial versus infratentorial), number of lesions (single versus multiple), and adjuvant chemotherapy and radiotherapy (RT).

For the analysis of survival in relation to a gener- al condition, patients were divided into two groups based on Karnofsky score ( $<70$ and $\geq 70)$.

\section{Statistical analysis}

Numerical data were presented as a mean and standard deviation. Relative frequencies were described as percentages. Kaplan-Meier curves were plotted for evaluation of survival, and the log-rank test was used for univariate analysis. Multivariate analysis was performed with Cox regression. The level of significance was set at $\mathrm{p}<0.05$. All analyses were carried out in SPSS 20.0.

\section{RESULTS}

Demographic data

We evaluated 71 patients (44 female and 27 male), with a mean age of $60.1 \pm 10.2$ years (range, 40 to 85 years). The mean age was $58.8 \pm 9.8$ years for women and $62.2 \pm 11.9$ years for men, with no significant difference between both groups.

\section{Clinical status}

Regarding functional status, 44 patients were assigned a Karnofsky score greater than or equal to 70 (62\%), while 27 patients had a Karnofsky score below 70 (38\%).

\section{Primary site of the tumor}

The most common primary site for cancer was the lung $(\mathrm{n}=29)$, followed by breast $(\mathrm{n}=24)$, kidney $(n=5)$, colon $(n=2)$, bladder $(n=2)$, and parotid gland $(n=2)$. There was one case each of melanoma, liver, laryngeal, thyroid, ovarian, and prostate cancers, and one cancer of unknown primary site (Figure 1).

\section{FIGURE 1. TUMOR TYPES.}

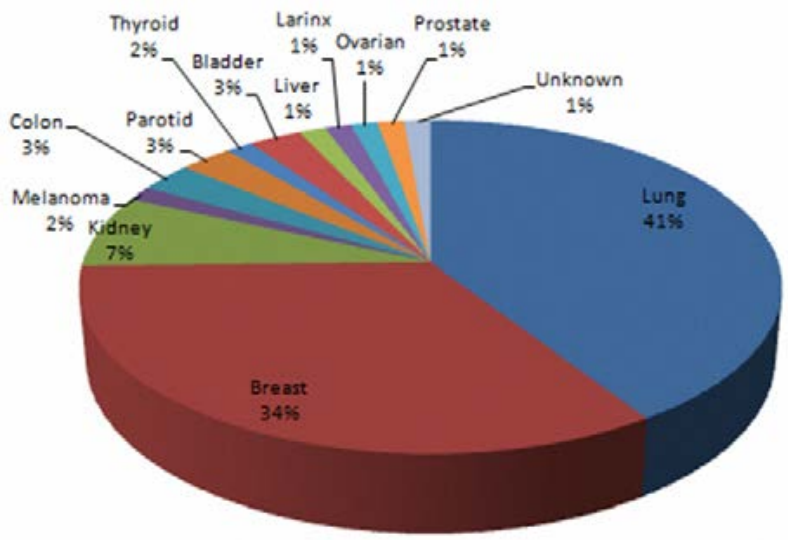




\section{Follow-up}

The mean length of follow-up was $30.5 \pm 13.62$ months (range, 1 to 47 months).

\section{Mortality}

At the end of the follow-up, 20 patients had died (28\%). Lung tumors accounted for most deaths $(n=$ 11), followed by breast $(\mathrm{n}=3)$ and kidney tumors $(\mathrm{n}=$ 3). One parotid tumor, one prostate tumor, and one cancer of unknown primary site were responsible for the other three deaths.

\section{Site and number of lesions}

Twelve patients had both supra- and infratentorial metastases (17\%); the remaining 59 (83\%) had supratentorial lesions only. No patients presented exclusively infratentorial lesions. Lesions were isolated in 43 patients (60.6\%) and multiple in 28 (39.4\%).

TABLE 1. SURVIVAL ACCORDING TO ANALYZED PARAMETER

\begin{tabular}{|c|c|c|c|c|}
\hline Parameter & Subgroup & $\begin{array}{l}\text { Number of } \\
\text { patients }\end{array}$ & $\begin{array}{l}\text { Survival } \\
\text { (months) }\end{array}$ & $p$ \\
\hline \multirow[t]{2}{*}{ Age } & $<60$ & 37 & 18.9 & $>0.05$ \\
\hline & $=o r>60$ & 34 & 14.8 & \\
\hline \multirow[t]{2}{*}{ Gender } & Female & 44 & 19.2 & $<0.05^{\star}$ \\
\hline & Male & 27 & 12.9 & \\
\hline \multirow[t]{2}{*}{ Karnofsky } & $<70$ & 27 & 13.4 & $>0.05$ \\
\hline & $=$ or $>70$ & 44 & 18.3 & \\
\hline \multirow[t]{2}{*}{ Chemotherapy } & Yes & 30 & 14.3 & $>0.05$ \\
\hline & No & 41 & 18.6 & \\
\hline \multirow[t]{2}{*}{ Radiotherapy } & Yes & 22 & 14.5 & $>0.05$ \\
\hline & No & 49 & 17.7 & \\
\hline \multirow{2}{*}{$\begin{array}{l}\text { Number of } \\
\text { lesions }\end{array}$} & Single & 42 & 16.7 & $>0.05$ \\
\hline & Multiple & 29 & 16.8 & \\
\hline \multirow[t]{2}{*}{ Lesion site } & $\begin{array}{l}\text { Supraten- } \\
\text { torial }\end{array}$ & 59 & 19.9 & $>0.05$ \\
\hline & $\begin{array}{l}\text { Supra and } \\
\text { infratentorial }\end{array}$ & 12 & 16.1 & \\
\hline \multirow[t]{3}{*}{ Tumor site } & Lung & 29 & 17.7 & $>0.05$ \\
\hline & Breast & 24 & 18.6 & \\
\hline & Other & 18 & 12.2 & \\
\hline
\end{tabular}

*: statistically significant when $p<0.05$.

\section{Adjuvant treatment}

Thirteen patients received adjuvant chemotherapy alone, 18 received both chemotherapy and radiotherapy, and four received radiotherapy alone.

\section{UNIVARIATE ANALYSIS (TABLE 1)}

Survival $\times$ Age

Patients were divided into two groups: $<60$ years $(\mathrm{n}=37)$ and $\geq 60$ years $(\mathrm{n}=34)$. The average survival after diagnosis of brain metastases was 18.9 months in patients aged $<60$ years and 14.8 months in those aged $\geq 60$. This difference was not statistically significant $(p=0.16)$.

\section{Survival × Gender}

The average survival after diagnosis of brain metastases was 19.2 months in women and 12.9 in men, a statistically significant difference $(p=0.008)$ (Figure 2).

\section{Survival $\times$ Karnofsky score}

Patients were divided into two groups: Karnofsky score $<70(\mathrm{n}=27)$ and $\geq 70(\mathrm{n}=44)$. The mean survival after diagnosis of brain metastasis was 13.44 months in patients with a Karnofsky score $<70$ and 18.34 months in those with a score $\geq 70$. The difference was not statistically significant $(p=0.84)$.

\section{Survival $\times$ Chemotherapy}

Median survival after diagnosis was 14.36 months in patients who underwent chemotherapy $(\mathrm{n}=31)$ and 18.62 months in those who did not $(n=40)$. The difference was not significant $(p=0.18)$.

\section{Survival $\times$ Radiotherapy}

Median survival after diagnosis was 14.57 months in patients who received radiotherapy $(\mathrm{n}=22)$ and 17.75 months in those who did not $(n=49)$. Again, the difference was not significant $(p=0.14)$.

\section{Survival $\times$ Number of lesions}

Mean survival after diagnosis of intracranial metastasis was 16.85 months in patients with multiple metastases $(n=29)$ and 16.76 months in those with single metastasis $(\mathrm{n}=42)$. There was no statistical significance $(p=0.91)$.

\section{Survival $\times$ Lesion site}

Mean survival after diagnosis of metastasis was 
19.9 months in patients with supratentorial metastases $(\mathrm{n}=59)$ and 16.15 months in patients with both supratentorial and infratentorial lesions $(\mathrm{n}=12)$. The difference was not significant $(p=0.44)$.

\section{Survival × Primary cancer site}

Median survival after diagnosis of brain metastases was 17.7 months in patients with lung cancer (n $=29), 18.6$ months in patients with breast cancer $(\mathrm{n}=$ 24), and 12.2 months in patients with other primary sites $(\mathrm{n}=18)$. The differences were not significant $(\mathrm{p}$ $=0.34)$.

\section{Multivariate analysis}

Multivariate analysis confirmed the results of the univariate analysis. The only variable with a significant impact on the survival curve was gender $(\mathrm{p}=0.02)$.

\section{DISCUSSION}

In adults, the primary tumors most often responsible for brain metastases are lung, breast, kidney, colorectal, and melanoma ${ }^{1,4}$. Nevertheless, up to $10 \%$ of metastases have an unknown primary source $\mathrm{e}^{2,3}$.

Metastatic tumors are a heterogeneous group with potentially varied treatment responses and survival rates. However, the presence of brain metastasis is understood to be indicative of poor prognosis and is considered the end stage of systemic malignancy. This is true not only because of the impact of such metastases on the central nervous system and their potentially disabling symptoms but also due

FIGURE 2. SURVIVAL BY GENDER.

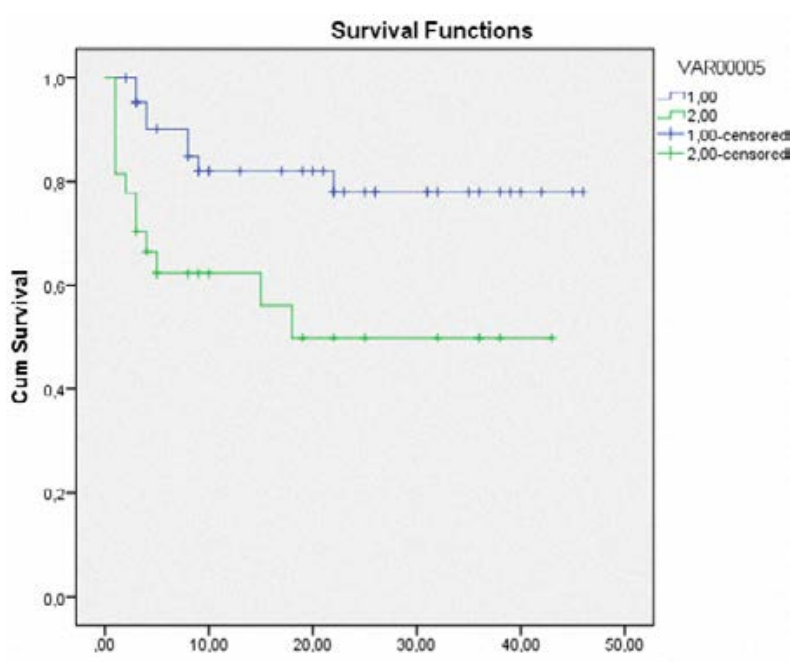

to a change in the biological behavior of the tumor, suggesting an aggressive state of invasiveness and spread, including a higher risk of metastases to other organs ${ }^{1-10}$.

Thus, it is important to consider various factors affecting the prognosis of these patients prior to therapeutic decision making ${ }^{1-14}$. A review showed that the benefit of surgical resection is to increase local recurrence-free time, with no impact on the duration of survival compared to non-surgical treatment. Previous studies have shown four factors associated with improved survival: Karnofsky score of 70 or higher, primary tumor type, age $<60$ years, and metastasis limited to the brain. Patients with all favorable characteristics might have a survival prognosis of 200 days in $52 \%$ of cases, whereas those without any of the favorable factors had an expected survival of 1.8 months $^{1-8}$.

Neurosurgical resection of such lesions is associated with a mean survival of 11 months (range, 6 to 16 months) and 1-year survival in $42 \%$ of patients (range, 22 to $63 \%$ ). Additionally, Patchell et al. ${ }^{2}$ reported a median survival of 16 months after surgery and RT compared to only 6 months after RT alone $\mathrm{e}^{7-10}$. However, proper selection of candidates for surgical resection is crucial. Some factors have been proposed as criteria for a surgical indication: imaging pattern (number, size, and site of lesions), histological type, radiosensitivity, and, especially, the stage of systemic disease ${ }^{10-15}$.

In our sample, lung and breast cancers were those most commonly implicated in the pathogenesis of metastatic tumors. This is consistent with the current literature ${ }^{1-13}$.

\section{INFERENCES}

Our study revealed that survival after surgical resection of brain metastases is highly variable, with an average of 16.6 months, ranging from less than 1 month to 46 months. Upon comparing survival curves according to the potential factors involved, the only variable associated with a significant difference was patient gender. None of the other factors (age, Karnofsky score, chemotherapy, radiotherapy, number of lesions, lesion location, and primary site) were associated with a difference in survival.

However, comparison of survival in patients with Karnofsky < 70 (18.34 months) versus > 70 (13.44 months) shows that the survival rate was higher in 
patients with a better clinical condition. Similarly, comparison of survival among patients aged $<60$ years (18.4 months) versus those aged $>60$ (14.8 months) shows that the survival rate was higher in younger patients. These findings suggest that patients with a better clinical condition at baseline also have a better prognosis, which may have clinical, but not statistical, significance.

In our sample, all patients with infratentorial lesions had supratentorial tumors as well. Overall, patients with infratentorial lesions had worse survival than those with supratentorial lesions, but the difference was not significant. These findings may suggest infratentorial tumors are associated with greater odds of multiple lesions, hydrocephalus, and increased risk of intracranial hypertension and death.

We did not disclose any significant impact of primary tumor site on survival time. This clearly suggests that, although primary tumors may behave differently due to distinct biological features in their original target organs, all share a similar aggressiveness curve once they become emboligenic and metastatic.

Predictably, the resection of brain metastases can treat brain diseases but does not alter the progression of the disease outside the nervous system. Failure to identify factors associated with prognosis suggests that the extent of the primary disease has a greater impact on survival than the assessed factors. Thus, resection of cerebral metastases may change acute survival curves due to the control of intracranial hypertension and improve quality of life by removing symptomatic masses. Nevertheless, systemic disease progression will be the determinant death cause. In other words, a patient with brain metastases should not die because of brain lesions if properly treated but will probably die as a result of the natural course of cancer itself.

The identification of gender as a factor related to survival probably reflects intrinsic differences between genders, such as hormonal aspects, the prevalence of specific cancers, and habits related to risk factors, such as smoking, alcoholism, and delay in diagnosis and initiation of cancer treatment. However, as these factors were not specifically studied, we can only conjecture as to their potential role.

Although our study is not comparative, the overall survival of the patients (16.6 months) suggests that neurosurgical resection of brain metastasis should continue to be performed.

\section{LIMITATIONS}

Interpretation of our results is limited by the retrospective nature of the study, nonrandomized design, and analysis restricted to surgical patients, which introduces selection bias. Data collection and analysis biases are also a concern. Another relevant limitation of our study was the small number of patients who received adjuvant therapy (13 receiving chemotherapy alone, four receiving RT alone, and 18 receiving both $\mathrm{RT}$ and chemotherapy). Although we do not know the precise reasons for this low adherence to adjuvant therapy, we believe it is due to loss of adequate oncology follow-up and, mainly, the unavailability of timely adjuvant treatment within the Brazilian public health care system.

Our study did not include an evaluation of surgical complications, which may impair but not invalidate our findings. Additionally, scales of postoperative life quality were not applied or described. We understand that life quality is as important as survival. However, our analyses were restricted to survival.

The lack of statistical significance may be explained by the fact that the analyzed factors do not capture the systemic nature of malignancy. Systemic disease may actually have as much or more impact on survival as cerebral metastatic disease.

\section{CONCLUSION}

Patients with cerebral metastases have approximately 16 months of survival after surgery. Survival is mainly defined by the systemic status of the disease and thus, except for gender, no evaluated variable impacted in survival curves.

\section{Ethical statement:}

- Funding: No funding source was used in this paper.

- Conflict of Interest: Authors declare no conflicts of interest

- Ethical approval: The current study was approved by HSPE Ethics and Research Committee.

- Informed consent: If necessary, all informed consent are available. 


\section{RESUMO}

OBJETIVO: Avaliar a sobrevivência de pacientes com metástases cerebrais tratados cirurgicamente de acordo com os fatores potencialmente envolvidos. Métodos: 71 pacientes tratados cirurgicamente foram analisados com o diagnóstico de metástases cerebrais durante o período de janeiro de 2011 a novembro de 2014, totalizando 47 meses de seguimento. A curva de Kaplan-Meier foi utilizada para análise de sobrevivência. Resultados: Avaliamos 71 pacientes com metástases cerebrais atendidas cirurgicamente, 44 do sexo feminino e 27 do sexo masculino, idade média de 60,1 anos. De acordo com a escala de Karnofsky, 44 pacientes foram classificados com Karnofsky maior ou igual a 70 e 27 pacientes com Karnofsky com menos de 70. O pulmão era o local mais comum. A morte ocorreu em 20 pacientes (28\%) e os tumores pulmonares são responsáveis pela maioria das mortes. Doze pacientes apresentavam metástases supra e infratentoriais, 59 apresentavam apenas lesões supratentoriais, e as lesões eram múltiplas em 28 pacientes e isoladas em 43. Trinta pacientes também foram tratados com quimioterapia, 18 foram tratados com quimioterapia e radioterapia, enquanto que apenas três receberam apenas radioterapia. A análise de sobrevivência pela curva de Kaplan-Meier não mostrou significância estatística de acordo com a idade, tipo histológico, localização, Karnofsky, quimioterapia e radioterapia. Houve significância estatística em relação ao gênero. Conclusão: Os fatores analisados não alteraram a sobrevivência, exceto o gênero. Este fato provavelmente pode ser explicado devido ao comportamento sistêmico e difuso do câncer.

PALAVRAS-CHAVE: Metástase neoplásica. Análise de sobrevida. Neoplasias. Prognóstico.

\section{REFERENCES}

1. Muacevic A, Wowra B, Siefert A, Tonn JC, Steiger HJ, Kreth FW. Microsurgery plus whole brain irradiation versus Gamma Knife surgery alone for treatment of single metastases to the brain: a randomized controlled multicentre phase III trial. J Neurooncol. 2008;87(3):299-307.

2. Patchell RA, Regine WF, Loeffler JS, Sawaya R, Andrews DW, Chin LS. Radiosurgery plus whole-brain radiation therapy for brain metastases. JAMA. 2006;296(17):2089-90

3. Suki D, Abouassi H, Patel AJ, Sawaya R, Weinberg JS, Groves MD. Comparative risk of leptomeningeal disease after resection or stereotactic radiosurgery for solid tumor metastasis to the posterior fossa. J Neurosurg. 2008;108(2):248-57.

4. Vecht Cl, Haaxma-Reiche $H$, Noordijk EM, Padberg GW, Voormolen $J \mathrm{H}$, Hoekstra FH, et al. Treatment of single brain metastasis: radiotherapy alone or combined with neurosurgery? Ann Neurol. 1993;33(6):583-90.

5. Bertolini F, Spallanzani A, Fontana A, Depenni R, Luppi G. Brain metastases: an overview. CNS Oncol. 2015;4(1):37-46.

6. Venur VA, Ahluwalia MS. Prognostic scores for brain metastasis patients: use in clinical practice and trial design. Chin Clin Oncol. 2015;4(2):18.

7. Gorovets D, Rava P, Ebner DK, Tybor DJ, Cielo D, Puthawala Y, et al. Predictors for long-term survival free from whole brain radiation therapy in patients treated with radiosurgery for limited brain metastases. Front Oncol. 2015;5:110.

8. Nieder C, Mehta MP. Prognostic indices for brain metastases: usefulness and challenges. Radiat Oncol. 2009;4:10.
9. Tevlin R, Larkin JO, Hyland JM, O'Connell PR, Winter DC. Brain metastasis from colorectal carcinoma: a single cancer centre experience. Ir J Med Sci. 2015;184(3):673-5.

10. Shen $Q$, Sahin AA, Hess KR, Suki D, Aldape KD, Sawaya R, et al. Breast cancer with brain metastases: clinicopathologic features, survival, and paired biomarker analysis. Oncologist. 2015;20(5):466-73.

11. Li Z, Zhang X, Jiang X, Guo C, Sai K, Yang Q, et al. Outcome of surgical resection for brain metastases and radical treatment of the primary tumor in Chinese non-small-cell lung cancer patients. Onco Targets Ther. 2015;8:855-60.

12. Kocher M, Soffietti R, Abacioglu U, Villà S, Fauchon F, Baumert BG, et al. Adjuvant whole-brain radiotherapy versus observation after radiosurgery or surgical resection of one to three cerebral metastases: results of the EORTC 22952-26001 study. J Clin Oncol. 2011;29(2):134-41.

13. Willett A, Wilkinson JB, Shah C, Mehta MP. Management of solitary and multiple brain metastases from breast cancer. Indian I Med Paediatr Oncol. 2015;36(2):87-93.

14. Soon $Y Y$, Tham IW, Lim KH, Koh WY, Lu II. Surgery or radiosurgery plus whole brain radiotherapy versus surgery or radiosurgery alone for brain metastases. Cochrane Database Syst Rev. 2014;(3):CD009454.

15. Arita H, Narita Y, Miyakita Y, Ohno M, Sumi M, Shibui S. Risk factors for early death after surgery in patients with brain metastases: re-evaluation of the indications for and role of surgery. J Neurooncol. 2014;116(1):145-52 